\title{
Debrief and its quality influence team culture.
}

\author{
Tul Laosakul ${ }^{1}$, Sein Son ${ }^{1}, J_{0}$ Derry $^{1}$, Laura Mitchell ${ }^{1}$, Arianna Ceretta ${ }^{1}$, and Mat Daniel ${ }^{1}$ \\ ${ }^{1}$ Nottingham University Hospitals NHS Trust
}

November 3, 2020

Five Key Points

- Team debrief is known to improve teamwork and safety.

- In our study of various staff groups, a third of did not have access to debrief.

- Exposure to team debrief was associated with better Culture of Care Barometer scores.

- Quality of debrief matters also: staff found structured, coaching and manager-led meetings to be more effective, useful and engaging than debriefs consisting of quick comments or informal discussion only.

- Debrief could be one of the ways to improve team culture.

Keywords: debrief, surgical specialties, culture, coaching, professional burnout, staff engagement, operating rooms, WHO Surgical Safety Checklist

\section{Introduction}

Debrief is a group reflective activity to discuss shared experiences, key in the Surgical Safety Checklist designed to reduce morbidity and mortality(1). Debrief promotes communication and teamwork, both leading factors in theatre incidents (2,3), and it can decompress and improve emotional reactions(4). Supportive and developmental workplace culture enhances staff engagement and wellbeing, reduces burnout(5), and fosters safe and compassionate patient care(6).

Debrief improves teamwork and safety, but there is less evidence of its impact on work culture. Using a questionnaire-based survey, we aimed to determine the impact of debrief on culture of care and on the likelihood that staff would recommend their team / hospital as a place to work; we hypothesised that debrief, especially high-quality debrief, will have a positive effect.

\section{Materials \& methods}

We undertook an anonymous, voluntary survey at one institution, inviting all nursing staff in ENT and ophthalmology theatres, plus nursing, admin and medical staff in ENT admin and clinics (estimated 128 staff). These areas were chosen to cover a range of staff groups and settings. Participants completed the following questionnaires:

- Debrief experience. Debrief was defined as "Team discussion about the day's events, for example at the end of a theatre list, at the end of a project, or at end of another session / event." We asked if staff had debrief, what style (see below), and "how effective, useful and engaging" each debrief style was for them.

- Culture of Care Barometer (CCB) assesses work culture within NHS including organisational values, team support, relationships with colleagues and job constraints $(6,7)$. It consists of 30 questions, with participants asked to indicate how much they agree with statements on a scale of 1 to 5 .

- Work promoter scores. Participants were asked how likely they would recommend their team and hospital as a place to work (10 point Likert scale, categorising 9-10 as promoters, 7-8 as passives, and 0-6 as detractors). 
Debrief types were described as follows

- quick comments (e.g. yes or no question)

- informal discussion (i.e. no specific structure)

- structured discussion (based on a framework or a checklist)

- coaching style (e.g. with cards or team games)

- team meetings led by a team leader / manager

Questionnaires were piloted in advance.

Statistical analyses were performed using SPSS Statistics 24 software. In the case of CCB and promoter scores the outcomes could not be attributed to one specific debrief type because the staff were exposed to many different types.

This study follows Standards for Quality Improvement Reporting Excellence (SQUIRE 2.0) as the reporting guideline.

\section{Results}

Description of staff taking part

Fifty participants took part, giving an estimated response rate of $39.1 \%$. Table 1 shows the responders' characteristics. ENT doctors who work across the three different areas were grouped with theatre staff because that is where most debrief occurred.

Female English as first language Disability Part-time employment

Ethnicity White Asian Black Mixed Other

Age group $<30$ years 31-40 years 41-50 years 51-60 years 61-70 years

Staff Group Nurse Admin Healthcare assistant Other theatre professional Doctor Other clinic professionals Student in thea Work setting Theatre Clinic Admin

Pay band 23456 Doctors

Debrief experience Experienced debrief Did not experience debrief Theatre staff experiencing debrief Clinic staff experiencir

Table 1: Characteristics of staff taking part. Not all 50 participants completed every question; denominators are shown.

\section{Effect of debrief on Culture of Care Barometer}

Higher CCB represent better culture of care. Amongst 47 completing the CCB, scores were higher in those who experienced debrief compared to those who did not (113.2 vs 99.7; two-tailed t test $\mathrm{p}=0.012$ ).

\section{Effect of debrief on promoter scores}

Effect of debrief on staff recommending team / hospital as a place to work is shown in Figure 1. Differences were not statistically significant.

Figure 1 to be inserted here.

\section{Debrief experience}

The frequency at which different types of debrief was experienced by the 33 staff is shown in Table 2 .

\begin{tabular}{lllllllll}
\hline Debrief Type & once & $\%$ & monthly & $\%$ & weekly & $\%$ & daily & $\%$ \\
\hline Quick comments & 0 & $0 \%$ & 3 & $9 \%$ & 18 & $55 \%$ & 9 & $27 \%$ \\
Informal discussion & 5 & $15 \%$ & 6 & $18 \%$ & 17 & $52 \%$ & 4 & $12 \%$ \\
Structured discussion & 2 & $6 \%$ & 9 & $27 \%$ & 9 & $27 \%$ & 5 & $15 \%$
\end{tabular}




\begin{tabular}{lllllllll}
\hline Debrief Type & once & $\%$ & monthly & $\%$ & weekly & $\%$ & daily & $\%$ \\
\hline Coaching style & 3 & $9 \%$ & 6 & $18 \%$ & 6 & $18 \%$ & 0 & $0 \%$ \\
Manager-led meeting & 1 & $3 \%$ & 13 & $39 \%$ & 2 & $6 \%$ & 9 & $27 \%$ \\
\hline
\end{tabular}

Table 2: Frequency of debrief types. Percentages refer to proportion of the 33 staff who experienced that particular type of debrief at that particular frequency.

Different debrief styles

The proportions of staff who found a particular style very or extremely effective, useful and engaging is shown in Table 3. The staff found structured, coaching and manager-led meetings to be more effective, useful and engaging than debriefs consisting of quick comments or informal discussion $(38 / 62$ experiences $(61.3 \%)$ vs 10/59 experiences $(16.9 \%)$; Chi squared $\mathrm{p}<0.001)$.

\begin{tabular}{ll}
\hline & $\begin{array}{l}\text { How many staff found it very or extremely } \\
\text { effective, useful and engaging. N/those } \\
\text { experiencing it and replying (\%) }\end{array}$ \\
\hline Debrief style & $4 / 29(13.8)$ \\
Quick comments & $6 / 30(20.0)$ \\
Informal discussion & $15 / 25(60.0)$ \\
Structured discussion & $8 / 14(57.1)$ \\
Coaching style & $15 / 23(65.2)$ \\
Manager-led team meeting &
\end{tabular}

Table 3. Staff opinion on debrief styles.

\section{Discussion}

Being exposed to debrief was associated with better Culture of Care Barometer scores. However, the differences in relation to recommending team / hospital as a place to work, were not statistically significant. Staff found structured, coaching and manager-led meetings to be more effective, useful and engaging than debriefs consisting of quick comments or informal discussion only.

Impact of debrief

There is overwhelming evidence that organisation with engaged staff achieve better outcomes: better patient experience, fewer errors, lower infection and mortality rates, better financial management, less work absence, and less burnout(8). Our findings that debrief is associated with higher CCB scores suggests that debrief may play a role wider than just the daily session itself. Whilst we observed differences in relation to recommending team / hospital as a place to work, these were not statistically significant, and the study underpowered for that outcome.

It is disappointing that over a third of our staff did not have access to debrief. Previous research has identified theatre debrief to be an important part of a comprehensive quality improvement programme, but its implementation is not straightforward. Leadership engagement and commitment are notable driving factors, in addition to meaningful and early debriefing feedback. On the other hand, loss of institutional commitment, resources and personnel might have a negative effect(9). It is important that there is a culture of openness, trust, and a willingness to explore challenges in a supportive and non-judgemental fashion, but this is not easy to achieve. Some staff may be reluctant to engage given debrief can identify their perceived failure and may feel uncomfortable to share their feelings with others; having a culture of learning and psychological safety is therefore key.

Different debrief styles 
We divided debrief into different styles based on what is commonly practiced in our departments. Debrief in theatres is mandatory although often is just quick comments with everyone rushing to leave or a discussion without a structure or purpose. Some debrief are checklist-based, with questions that the team works through. Some team leaders have daily or weekly team meetings led by the leader, where recent events (as well as forwards planning) are discussed. One of the authors (MD) uses coaching-style debrief utilising coaching tools and principles (recognised by the team because cards, games or activities are often used). Coaching has the potential to increase self-efficacy and determination to counterbalance burnouts and improve personal resilience; these are vital qualities in the healthcare professions(10).

There is a wide variety of debrief styles used just in our unit, and there is no one right way of doing debrief. There is limited evidence on which is best, particularly when each team has unique needs or goals. Moreover, it is important that debrief is responsive to team needs, team culture, and leadership style, as different teams can achieve the same high quality outcomes using quite different ways of working.

It was clear that quick comments and informal discussion were most frequently encountered debrief styles, yet our staff found them less effective than the other styles. Thus, quality of debrief matters, although the exact style may be less important than its quality.

Should everyone undertake debriefing?

We recognise that in many units, timetabling of staff activities has developed over decades, and finding a slot for debriefing may not be possible nor appropriate. We are not suggesting that every team should start daily debriefing. It is quite possible to develop great teams using methods other than debrief. But if a team / leader is looking to change and develop team culture, then debrief could be one of the ways that this could be achieved.

\section{Limitations}

We report what staff thought, and examined associations between debrief and outcomes. However, debrief does not happen in isolation from the rest of teamwork, culture and leadership, and it is therefore not possible to claim that debrief is the cause of better culture scores. The problem of associations and apportioning effect is common in workplace culture studies, where it is (usually) not possible to conduct experiments in controlled circumstances and changing just one variable at a time.

A large proportion of our respondents worked in theatres, which may have affected the results. Future, studies could include a larger number of staff from a wider clinical setting; however, studying this in a wider context may be more difficult if the researchers do not understand in detail what kind of debrief takes place. A larger study could also have the ability to test specific constructs/questions, with sufficient power to demonstrate a statistical difference.

We used a limited number of outcomes, and this, together with use of composite outcomes, is also a limitation. CCB is a published tool that examines different attributes of NHS organisational culture, whilst the promoter scores capture work engagement from a different angle. There is a myriad of possible outcomes that could be used, with resultant increase in complexity. Nevertheless, our simple and practical approach suggests that debrief, and its quality, matter.

\section{Conclusion}

Being exposed to debrief led to higher Culture of Care Barometer scores. Additionally, our staff found structured, coaching and manager-led meetings to be more effective, useful and engaging than debriefs consisting of quick comments or informal discussion only. Having a team debrief matters.

\section{Data availability statement}

The data generated from this study, and that support the findings of this study are available from the corresponding author upon reasonable request.

\section{References}


1. Haynes AB, Weiser TG, Berry WR, Lipsitz SR, Breizat AHS, Dellinger EP, et al. A surgical safety checklist to reduce morbidity and mortality in a global population. N Engl J Med. 2009;360(5):491-9.

2. Cadman V. The impact of surgical safely checklists on theatre departments: A critical review of the literature. J Perioper Pract. 2016;26(4):62-71.

3. Gawande AA, Zinner MJ, Studdert DM, Brennan TA. Analysis of errors reported by surgeons at three teaching hospitals. Surgery. 2003;133(6):614-21.

4. Eng J, Schulman E, Jhanwar SM, Shah MK. Patient Death Debriefing Sessions to Support Residents' Emotional Reactions to Patient Deaths. J Grad Med Educ. 2015;7(3):430-6.

5. McKinley N, McCain RS, Convie L, Clarke M, Dempster M, Campbell WJ, et al. Resilience, burnout and coping mechanisms in UK doctors: a cross-sectional study. BMJ Open. 2020;10(1):e031765.

6. The King's Fund. Culture and leadership programme Discover Concepts and evidence.

7. Rafferty AM, Philippou J, Fitzpatrick JM, Pike G, Ball J. Development and testing of the ' Culture of Care Barometer' ( CoCB ) in healthcare organisations : a mixed methods study. 2017;1-8.

8. The King's Fund. Leadership and Engagement for Improvement in the NHS - Together We Can. Leadersh Heal Serv. 2012;25(4):133-9.

9. Brindle ME, Henrich N, Foster A, Marks S, Rose M, Welsh R, et al. Implementation of surgical debriefing programs in large health systems: An exploratory qualitative analysis. BMC Health Serv Res. 2018;18(1):114.

10. Galaiya R, Kinross J, Arulampalam T. Factors associated with burnout syndrome in surgeons: a systematic review. Ann R Coll Surg Engl. 2020;1-8.

List of Figures. Total number of figures $=1$.

Figure 1: Effect of debrief on how likely staff would be to recommend their team (top) and hospital (bottom) as a place to work, split into promoters (scores 9-10), passives (scores 7-8), and detractors (scores 0-6). 
FIGURES

TOTAL NUMBER OF FIGURES = 1
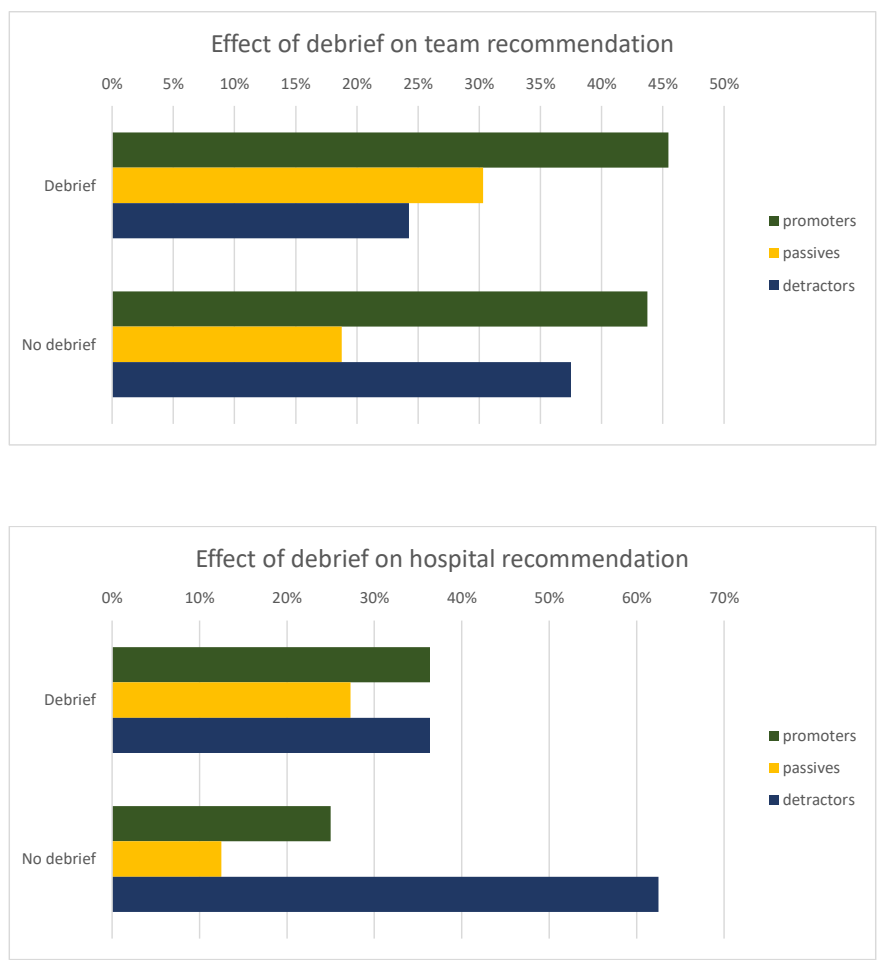

Figure 1: Effect of debrief on how likely staff would be to recommend their team (top) and hospital (bottom) as a place to work, split into promoters (scores 9-10), passives (scores 7-8), and detractors (scores 0-6). 